\title{
CHARACTERIZATION OF RESIDUAL STRESSES IN GRADED CERAMIC-METAL STRUCTURES: A COMPARISON OF DIFFRACTION EXPERIMENTS AND FEM CALCULATIONS
}

\author{
B. H. Rabin and R. L. Williamson \\ Idaho National Engineering Laboratory \\ P.O. Box 1625 \\ Idaho Falls, Idaho, USA 83415-2218
}

\author{
T. R. Watkins, X.-L. Wang, C. R. Hubbard and S. Spooner \\ Oak Ridge National Laboratory \\ P.O. Box 2008 \\ Oak Ridge, TN, USA 37831-6064
}

\section{INTRODUCTION}

Numerical models have been extensively developed for predicting the thermomechanical behavior of ceramic-metal joints containing graded interlayers. The goal of such modeling is to be able to design optimum interlayer microstructural characteristics required to meet the needs of specific application conditions, and to use this design information to guide component fabrication. In order to have confidence in the outcome of these modeling efforts, it is critical that the models be validated by comparison with experimental results, at least for some model systems and simple specimen geometries. In this study, residual strain and stress distributions are being studied using a combination of FEM calculations and diffraction techniques.

The graded specimen examined in this research was fabricated by powder processing methods. $\mathrm{Al}_{2} \mathrm{O}_{3}-\mathrm{Ni}$ was selected as a model system. The residual stresses expected in the specimen were predicted by FEM calculations using an elastic-plastic model. Strain and stress distributions in the specimen were characterized experimentally using $x$-ray and neutron diffraction techniques. In this paper, preliminary experimental results are presented and compared with model predictions.

\section{EXPERIMENTAL}

\subsection{Specimen Fabrication}

The steps involved in the production of the graded $\mathrm{Ni}_{-} \mathrm{Al}_{2} \mathrm{O}_{3}$ specimen included powder selection, incorporation of sintering aids and binders, mixing desired powder compositions, layering powders in a die, compaction, debinding and sintering, and final consolidation by hot isostatic pressing (HIP). Details of the specimen preparation have been presented previously $[1,2]$.

$$
\text { V. DISTRIBUTION OF THIS DOCUMENT IS UNLIMITED }
$$


Figure 1 shows the cylindrical $\mathrm{Ni}-\mathrm{Al}_{2} \mathrm{O}_{3}$ specimen examined in these experiments, along with the microstructures within the graded interlayer. The joined specimen was approximately $40 \mathrm{~mm}$ in length and $9 \mathrm{~mm}$ in diameter. Intermediate stepwise compositions of $20,40,60$ and 80 vol.\% Ni were used, and the joint was linearly graded over a thickness of approximately $12 \mathrm{~mm}$. Note the distinct transition in microstructure that has been achieved in the composite interlayers by controlling the starting $\mathrm{Al}_{2} \mathrm{O}_{3}$ and $\mathrm{Ni}$ particle sizes during fabrication. Specifically, the 20 and 40 vol.\% Ni layers (fabricated using $0.5 \mu \mathrm{m} \mathrm{Al}_{2} \mathrm{O}_{3}$ and 18 $\mu \mathrm{m} \mathrm{Ni)} \mathrm{exhibit} \mathrm{a} \mathrm{continuous} \mathrm{ceramic} \mathrm{matrix} \mathrm{with} \mathrm{dispersed} \mathrm{metal} \mathrm{particles,} \mathrm{whereas}$ the 60 and 80 vol.\% layers (fabricated using $22 \mu \mathrm{m} \mathrm{Al} \mathrm{O}_{3}$ and $5 \mu \mathrm{m} \mathrm{Ni}$ ) exhibit a continuous metallic matrix with dispersed ceramic particles. The use of a submicron ceramic particle size in the ceramic-rich layers is necessary to achieve adequate densification of these composites, and the change to a large ceramic:metal particle size ratio in the metal-rich layers allows a continuous metal matrix to be obtained in these composite microstructures.

\subsection{FEM Modeling}

Continuum models were used to compute residual stresses and strains developed in the joined $\mathrm{Al}_{2} \mathrm{O}_{3}-\mathrm{Ni}$ specimen during simulated cooling from $1100 \mathrm{~K}$ to room temperature. Figure 2 shows the specimen geometry and mesh used in the analysis. Because both the specimen and its loading (thermal) are axisymmetric, it is possible to restrict models to two dimensions. Spatially uniform cooling was assumed, thus only the equations of stress equilibrium need to be solved. The graded region was treated as a series of four perfectly bonded composite interlayers, each layer being assigned different material properties. Material behavior was assumed to be independent of time (no creep). The $\mathrm{Al}_{2} \mathrm{O}_{3}$ was assumed to remain elastic, with plasticity permitted within the $\mathrm{Ni}$ and any interlayer materials; a von Mises yield condition and isotropic hardening were utilized.

IInearty graded specimen

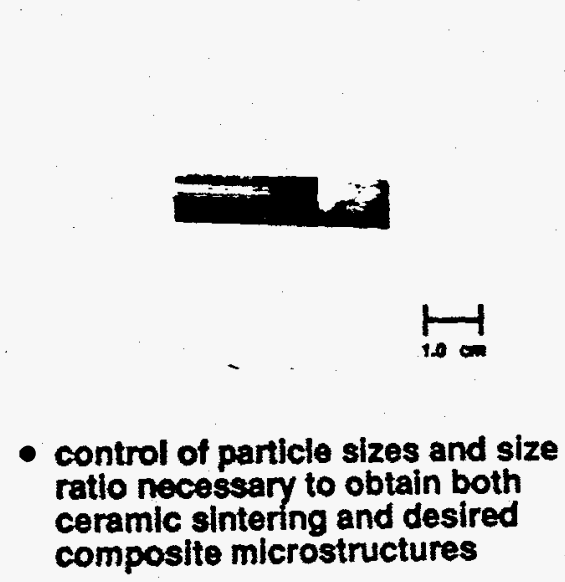

microstructures

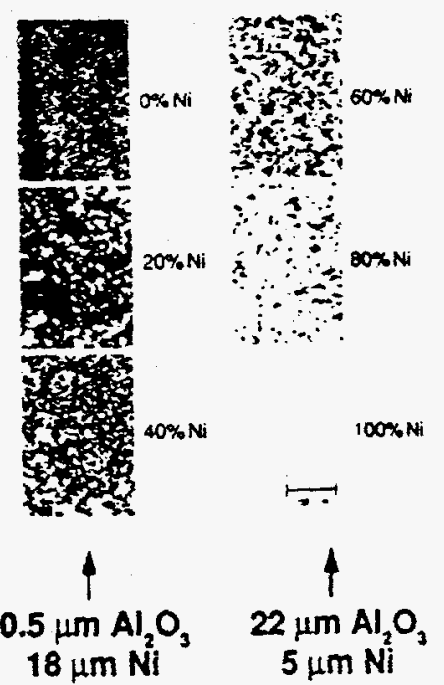

Figure 1. Photograph showing the graded $\mathrm{Al}_{2} \mathrm{O}_{3}-\mathrm{Ni}$ specimen examined in this study along with the microstructures observed within the graded interlayer. 


\section{DISCLAIMER}

This report was prepared as an account of work sponsored by an agency of the United States Government. Neither the United States Government nor any agency thereof, nor any of their employees, makes any warranty, express or implied, or assumes any legal liability or responsibility for the accuracy, completeness, or usefulness of any information, apparatus, product, or process disclosed, or represents that its use would not infringe privately owned rights. Reference herein to any specific commercial product, process, or service by trade name, trademark, manufacturer, or otherwise does not necessarily constitute or imply its endorsement, recommendation, or favoring by the United States Government or any agency thereof. The views and opinions of authors expressed herein do not necessarily state or reflect those of the United States Government or any agency thereof. 


\section{DISCLAIMER}

Portions of this document may be illegible in electronic image products. Images are produced from the best available original document. 
Stress-strain constitutive parameters for composite interlayers were computed using a modified rule-of-mixtures approach using temperature dependent mechanical property and thermal expansion values. Details of the FEM model, including assumptions regarding constitutive behavior, have been presented previously [2-4]. Numerical solutions were obtained using the ABAQUS finite element computer program [5].

\subsection{Diffraction Measurements}

Elastic strains were measured along the surface and within the interior of the specimen using $x$-ray and neutron diffraction techniques, respectively. The $x$-ray measurements were based on the well known " $\sin ^{2} \psi$ method" [6]. Figure 3 shows the coordinate system used. Referring to this figure, the general equation for strain measurement can be expressed as

$$
\begin{aligned}
\left(\varepsilon_{33}\right)_{\phi, \psi}=\frac{d_{\phi, \psi}-d_{0}}{d_{0}}= & \varepsilon_{11} \cos ^{2} \phi \sin ^{2} \psi+\varepsilon_{12} \sin 2 \phi \sin ^{2} \psi \\
& +\varepsilon_{22} \sin ^{2} \phi \sin ^{2} \psi+\varepsilon_{33} \cos ^{2} \psi \\
& +\varepsilon_{13} \cos \phi \sin 2 \psi+\varepsilon_{23} \sin \phi \sin 2 \psi
\end{aligned}
$$

which for an isotropic material allows stresses to be calculated according to

$$
\begin{aligned}
\left(\dot{\varepsilon}_{33}\right)_{\phi, \psi}=\frac{d_{\phi, \psi}-d_{0}}{d_{0}}= & \frac{1+v}{E}\left(\sigma_{11} \cos ^{2} \phi+\sigma_{12} \sin 2 \phi+\sigma_{22} \sin ^{2} \phi-\sigma_{33}\right) \sin ^{2} \psi \\
& +\frac{1+v}{E} \sigma_{33}-\frac{v}{E}\left(\sigma_{11}+\sigma_{22}+\sigma_{33}\right) \\
& +\frac{1+v}{E}\left(\sigma_{13} \cos \phi+\sigma_{23} \sin \phi\right) \sin 2 \psi
\end{aligned}
$$

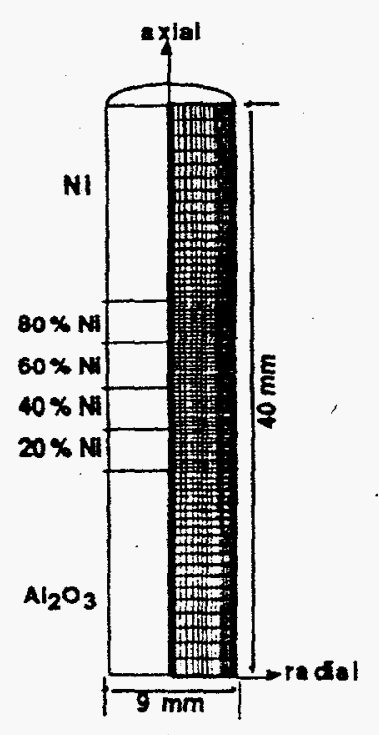

Figure 2. Specimen geometry and mesh used in the FEM calculations.
Residual strains within the pure $\mathrm{Al}_{2} \mathrm{O}_{3}$ result from the thermal expansion mismatch between the $\mathrm{Al}_{2} \mathrm{O}_{3}$ and the remainder of the structure to which it is joined. Within the composite interlayers, however, both macro- (between layers) and microstrains (between phases) exist. According to Noyan and Cohen [6], the total strain measured within each phase of the composite is the sum of the macro- and micro-components, such that, in the case of Ni for example

$$
\sigma_{i j}^{\top}(N i)=\sigma_{i j}^{m}+\sigma_{i j}^{\mu}(N i)
$$

Macrostresses are the same for both phases in the composite, however, microstresses must be balanced according to

$$
(1-f) \sigma_{i j}^{\mu}\left(\mathrm{Al}_{2} \mathrm{O}_{3}\right)+f \sigma_{i j}^{\mu}(\mathrm{Ni})=0
$$

Since the FEM model we have adopted predicts only macrostresses, experimental data taken from composite layers must be separated into macro- and micro-components using 


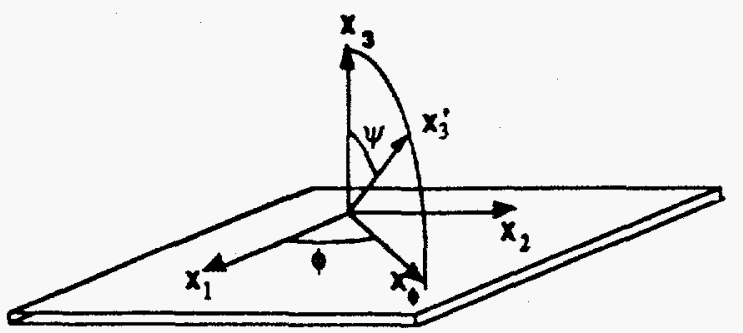

Figure 3. Coordinate system used for diffraction experiments. focused on this region of the specimen. Data was collected from within the pure $\mathrm{Al}_{2} \mathrm{O}_{3}$ and only the first few composite interlayers. Results are reported in terms of specific strain or stress components for the interior of the specimen (neutron measurements) or along the surface of the cylindrical specimen ( $x$-ray measurements).

The most critical stress responsible for causing fracture is the axial tensile stress within the $\mathrm{Al}_{2} \mathrm{O}_{3}$ along the surface of the specimen. Figure 4 shows this stress component as measured by $\boldsymbol{x}$-ray diffraction and as predicted by FEM modeling. For both the modeling and experimental results the peak tensile stress exists within the $\mathrm{Al}_{2} \mathrm{O}_{3}$ close to the interface between the $\mathrm{Al}_{2} \mathrm{O}_{3}$ and the $20 \% \mathrm{Ni}$ composite layer. Note that the magnitude of the peak stress measured experimentally is significantly lower than that predicted by the model. The peak value predicted by the model can be made to agree more closely with the experimental value by taking into account porosity effects on $\mathrm{Al}_{2} \mathrm{O}_{3}$ properties and creep effects within the $\mathrm{Ni}$ [7]. Within the composite interlayers the macrostress measured experimentally shows cyclic variations similar to those predicted by the model, however, close agreement between the measured and predicted values

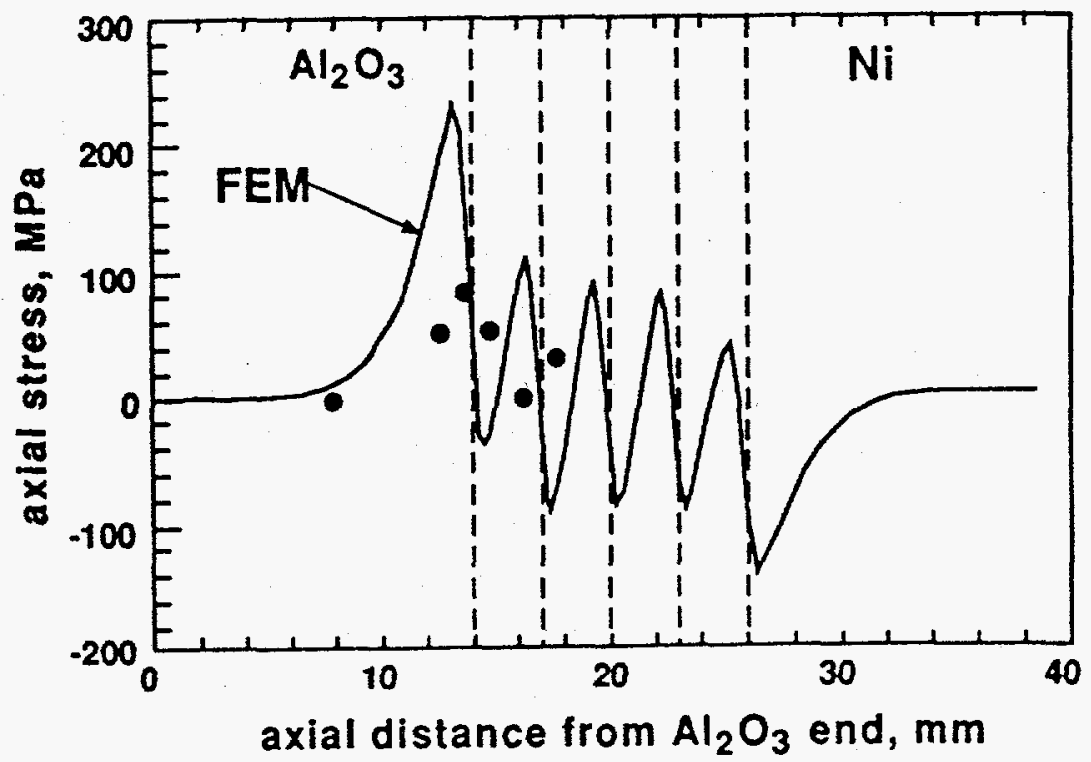

Figure 4. X-ray diffraction results measured along the specimen surface showing the axial stress as a function of position. The FEM prediction is shown for comparison. 


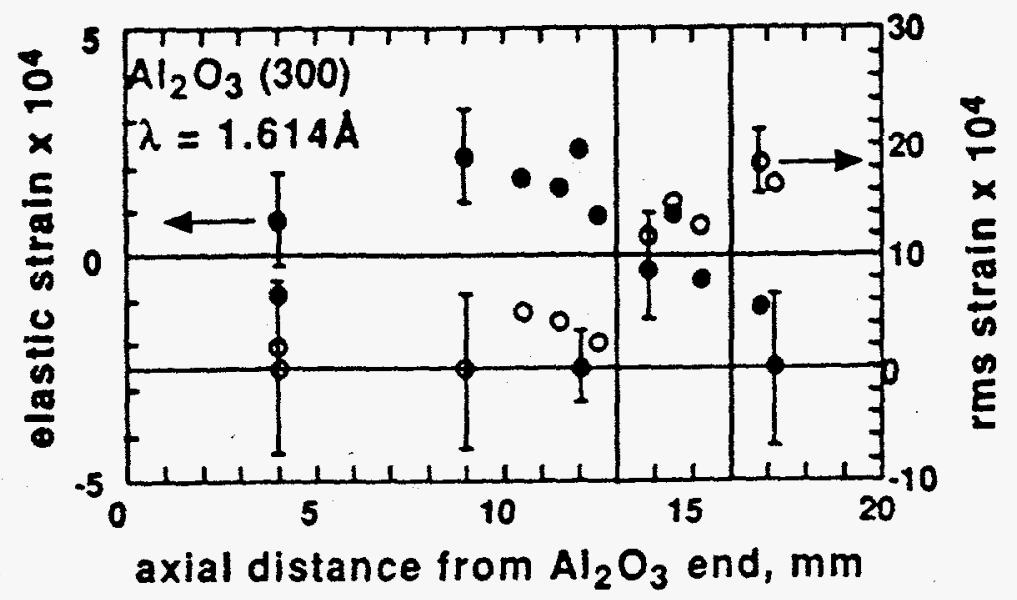

Figure 5. Neutron diffraction results showing the radial strain measured atong the axis of symmetry as a function of position. The rms microstrain cakculated from peak broadening is also shown.

was not obtained.

Figure 5 shows the radials strains measured by neutron diffraction along the centerline of the specimen, as well as the rms microstrain determined from a simple line broadening analysis. The following observations can be made regarding this data. First, the magnitudes of the strains are quite small, in all cases less than $5 \times 10^{-4}$. Secondly, and perhaps most importantly, tensile radial strains were experimentally observed within the $\mathrm{Al}_{2} \mathrm{O}_{3}$, whereas, since the ceramic has a lower coefficient of thermal expansion than the metal, these strains are expected to be compressive. The rms microstrain is very low in the pure $\mathrm{Al}_{2} \mathrm{O}_{3}$ and increases within the $20 \%$ and $40 \%$ Ni composite interlayers.

Finally, Figure 6 shows the axial strain within the $\mathrm{Al}_{2} \mathrm{O}_{3}$ as a function of radial position measured at a location $0.7 \mathrm{~mm}$ from the interface between the pure $\mathrm{Al}_{2} \mathrm{O}_{3}$ and the $20 \% \mathrm{Ni}$ composite layer. Starting from the axis of symmetry and moving outward toward the radial free edge the axial strain was observed to be quite low, as predicted by the FEM model. However, very close to the radial free surface the model predicts a rapid increase in tensile strain which could not be observed experimentally due to the limited practical spatial resolution of the neutron diffraction sampled volume.

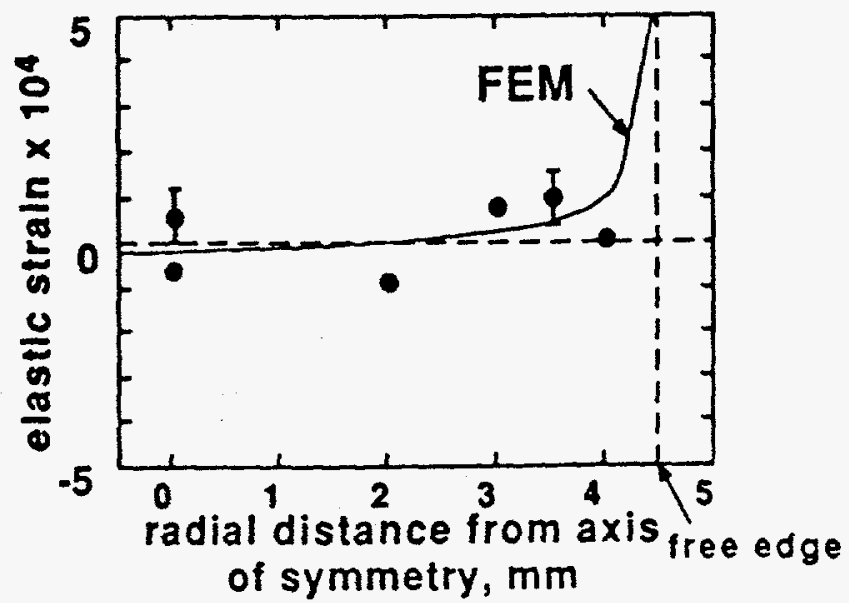

Figure 6. Neutron diffraction results showing the axial strain as a function of radial position within the pure $\mathrm{Al}_{2} \mathrm{O}_{3}$ at a location $0.7 \mathrm{~mm}$ from the $\mathrm{Al}_{2} \mathrm{O}_{3} / \mathrm{FGM}$ interface. 
The reasons for the apparent disagreement between the experimental results and the FEM predictions are not clear at this time. In the case of the lower axial stress within the $\mathrm{Al}_{2} \mathrm{O}_{3}$ measured by $x$-ray diffraction on the specimen surface (Figure 4), there are always questions regarding the validity of the constitutive assumptions used in the FEM model that could account for this discrepancy. Other potential explanations include possible microcracking stress relief within the ceramic, or the influence of surface preparation. Regarding the radial strain along the axis of symmetry (Figure 5), however, the apparent existence of tensile strains within the $\mathrm{Al}_{2} \mathrm{O}_{3}$ is more puzzling. It would seem that this result would only be possible if the thermal expansion coefficients did not vary with volume fraction in a monotonic fashion, as would be expected from the rule-of-mixtures. Detailed characterization of the expansion coefficient and mechanical properties (elastic modulus and yield strength) of the individual composite materials used as interlayers is now being performed in an effort to address these questions. In addition, neutron and $x$-ray diffraction experiments will be carried out in the future on a single composite interlayer joint (e.g. $60 \% \mathrm{Ni}$ ) in which the stress and strain distributions are expected to be less complicated.

\section{CONCLUSIONS}

The residual strains and stresses in a powder processed axisymmetric $\mathrm{Al}_{2} \mathrm{O}_{3}-\mathrm{Ni}$ graded specimen have been characterized by a combination of numerical and experimental techniques. Preliminary neutron and $x$-ray diffraction measurements were not in very good agreement with FEM model predictions, particularly regarding the in-plane stresses along the axis of symmetry. These results suggest additional diffraction measurements on graded specimens having fewer interlayers should be carried out, and experimental verification of the constitutive assumptions used in the FEM model is needed.

\section{REFERENCES}

[1] Rabin, B. H. and Williamson, R. L., "Design and Fabrication of Ceramic-Metal Gradient Materials," Processing and Fabrication of Advanced Materials, V. A. Ravi, T. S. Srivatsan and J. J. Moore (eds.), The Minerals, Metals and Materials Society, Warrendale, PA, 1994, p. 145.

[2] Rabin, B. H. and Heaps, R. J., "Powder Processing of $\mathrm{Ni}_{-} \mathrm{Al}_{2} \mathrm{O}_{3} \mathrm{FGM}$," Ceramic Trans., 34, 1993, p. 173.

[3] Williamson, R. L., Rabin, B. H. and Drake, J. T., "Finite Element Analysis of Thermal Residual Stresses at Graded Ceramic/Metal Interfaces, Part I: Model Description and Geometrical Effects," Journal of Applied Physics, 74, 1993, p. 1310.

[4] Drake, J. T., Williamson, R. L. and Rabin, B. H., "Finite Element Analysis of Thermal Residual Stresses at Graded Ceramic/Metal Interfaces, Part II: Optimization for Residual Stress Reduction," Journal of Applied Physics, 74, 1993. p. 1321.

[5] Computer code ABAQUS, Hibbitt, Karlsson, and Sorensen, Inc., Providence, RI, 1992.

[6] Noyan, I. C. and Cohen, J. B., "Residual Stress: Measurement by Diffraction and Interpretation," Springer-Verlag, New York, 1987.

[7] Williamson, R. L. and Rabin, B. H., unpublished results, 1994.

Part of this research was supported by the U. S. Department of Energy, Assistant Secretary for Energy Efficiency and Renewable Energy, Office of Transportation Technologies, as part of the High Temperature Materials Laboratory User Program under contract DE-AC05$840 R 21400$, managed by Martin Marietta Energy Systems, Inc. 